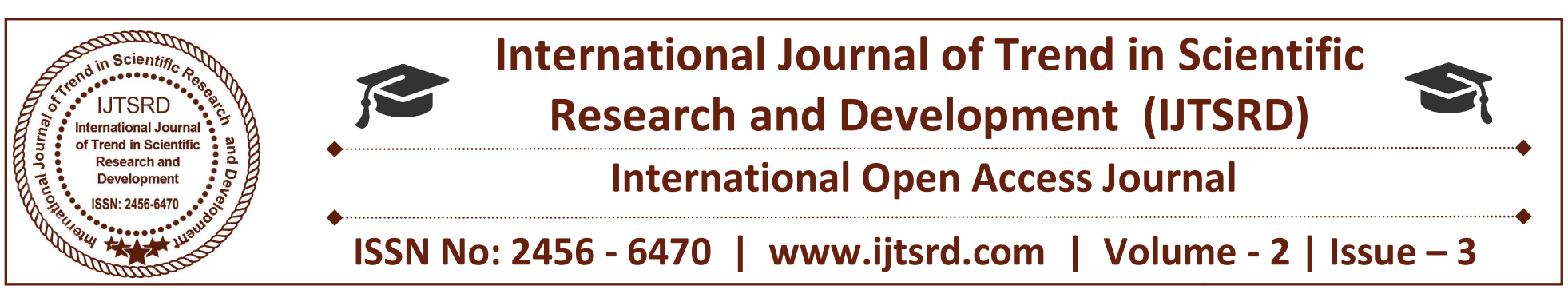

\title{
A Review on Power Electronics based Compensators in Grid Connected WECS
}

\author{
Zahid Hassan \\ M.Tech Scholar, Electrical Engineering Department \\ YIET, Gadhauli, Yamunanagar, Haryana, India
}

\author{
Gagan Deep Yadav \\ A.P., Electrical Engineering Department \\ YIET, Gadhauli, Yamunanagar, Haryana, India
}

\section{ABSTRACT}

This paper gives a review on the power electronic applications for wind energy conversion systems. Various wind turbine systems with different generators and power electronic converters are described, and different technical features are compared. The electrical topologies of wind farms with different wind turbines are summarized and the possible uses of power electronic converters with wind farms are shown. In conclusion, the possible methods of using the power electronic technology for improving wind turbine performance in power systems to meet the main grid connection requirements are discussed.

\section{INTRODUCTION}

Over the last ten years, the global wind energy capacity has increased rapidly and became the fastest developing renewable energy technology. By the end of 2017, the global wind electricity-generating capacity has increased to $539 \mathrm{GW}$ from $514 \mathrm{GW}$ in 2016. The early technology used in wind turbines was based on squirrel-cage induction generators (SCIGs) directly connected to the grid. Recently, the technology has developed toward variable speed. The controllability of the wind turbines becomes more and more important as the power level of the turbines increases. Power electronic, being the technology of efficiently converting electric power, plays an important role in wind power systems. It is an essential part for integrating the variable-speed wind power generation units to achieve high efficiency and high performance in power systems. Even in a fixedspeed wind turbine system where wind power generators are directly connected to the grid, thyristors are used as soft-starters. The power electronic converters are used to match the characteristics of wind turbines with the requirements of grid connections, including frequency, voltage, control of active and reactive power, harmonics, etc. small-size filters. Fig. 2 shows a typical power electronic converter consisting of self-commutated semiconductors such as IGBTs. Other types of circuit configurations also exist, including the multilevel converters, as shown in Fig. 4, and the matrix converter, as shown in Fig. 5. Especially, the multilevel converters are very interesting in such applications due to the voltage level of the converters and the decrease of the harmonics, and consequently, the size of the output filters. The matrix converter is technically more complicated.

\section{INTRODUCTION OF WIND ENERGY CONVERSION SYSTEMS}

The main components of a wind turbine system are illustrated in Fig. 1, including a turbine rotor, a gearbox, a generator, a power electronic system, and a transformer for grid connection. Wind turbines capture the power from wind by means of turbine blades and convert it to mechanical power. It is important to be able to control and limit the converted mechanical power during higher wind speeds [1], [2]. It can be seen that the power may be smoothly limited by rotating the blades either by pitch or active stall control while the power from a stall-controlled turbine shows a small overshoot and a lower power output for higher wind speed. The common way to convert the low-speed, high-torque mechanical power to electrical power is using a gearbox and a generator 
with standard speed. The gearbox adapts the low speed of the turbine rotor to the high speed of the generator, though the gearbox may not be necessary for multi-pole generator systems. The generator converts the mechanical power into electrical power, which being fed into a grid possibly through power electronic converters, and a transformer with circuit breakers and electricity meters. The two most common types of electrical machines used in wind turbines are induction generators and synchronous generators. Induction generators with cage rotor can be used in the fixed-speed wind turbines due to the damping effect. The reactive power necessary to energize the magnetic circuits must be supplied from the network or parallel capacitor banks at the machine terminal that may have the danger of self-excitation, when connection to the network is lost. In such a case, the terminal voltage or reactive power may not be directly controlled, and the induction generators may suffer from voltage instability problem, which is becoming a significant concern with large-scale wind farm penetration. A wound rotor induction machine has a rotor with copper windings, which can be connected to an external resistor or to ac systems via power electronic systems. Such a system provides a partial variable-speed operation with a small power electronic converter, and therefore increased energy capture and reduced mechanical load to the system. This type of system is an economical way to supply reactive power and obtain variable speed for increased energy yield at wind speeds below the rated speed. Synchronous generators are excited by an externally applied $\mathrm{dc}$ or by permanent magnets (PMs). There is considerable interest in the application of the multiple pole synchronous generators (either with PM excitation or with an electromagnet) driven by a wind-turbine rotor without a gearbox or with a low ratio gearbox. Synchronous machines powered by wind turbines may not be directly connected to the ac grid because of the requirement for significant damping in the drive train. The use of a synchronous generator leads to the requirement for a full rated power electronic conversion system to decouple the generator from the network. While most of the turbines are nowadays connected to the medium-voltage system, large offshore wind farms may be connected to the highvoltage and extra high-voltage systems. The transformer is normally located close to the wind turbines to avoid high current flowing in long lowvoltage cables. The electrical protection system of a wind turbine system protects the wind turbine as well as secures the safe operation of the network.

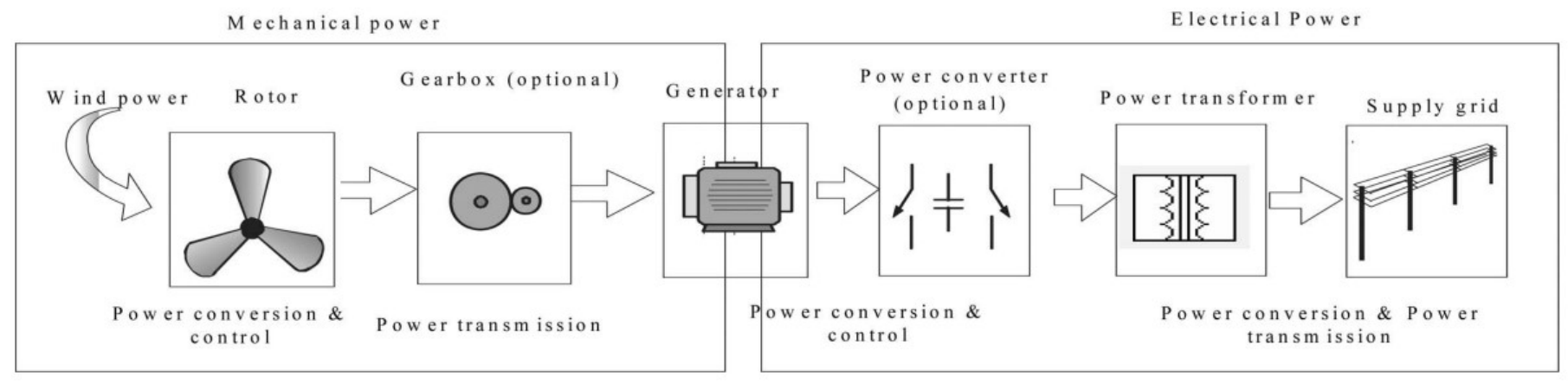

Fig. 1. Main components of a wind turbine system. 


\section{Modern Power Electronics}

Power electronics has changed rapidly during the last 30 years and the number of applications has been increasing, mainly due to the developments of the semiconductor devices and the microprocessor technology. For both cases, the performance is steadily increasing, and at the same time, the price of devices is continuously falling. In order to improve reliability and reduce cost, the number of components is going down by a higher level of integration. The power electronic device technology is still undergoing important progress, including some key self-commutated devices, such as insulated gate bipolar transistor (IGBT), MOSFET, integrated gate commutated thyristor (IGCT), MOS-gate thyristors, and silicon carbide FETs. The breakdown voltage and/or current carrying capability of the components are also continuously increasing. Important research is going on to change the material from silicon to silicon carbide. This may dramatically increase the power density of the power converters. Power electronic converters are constructed by semiconductor devices, driving, protection, and control circuits to perform voltage magnitude and frequency conversion and control. A converter, depending on the topology and application, may allow both directions of power flow. There are two different types of converter systems: grid commutated and self-commutated converter systems. The grid commutated converters are mainly thyristor converters with high power capacity of 6 or 12 or even more pulses. A thyristor converter consumes inductive reactive power and it is not able to control the reactive power. Thyristor converters are mainly used for very high voltage and power applications, such as conventional HVDC systems. Selfcommutated converter systems normally adopt pulsewidth-modulated (PWM) control methods; the semiconductors with turn-OFF ability, such as IGBTs, are mainly used. This type of converter may transfer both active power and reactive power [3], [4] in both directions (ac-dc or dc-ac). This means that the reactive power demand can be delivered by a PWM converter. The high-frequency switching of a PWM converter may produce harmonics and inter harmonics, which, in general, are in the range of some kilohertz. Due to the high frequencies, the harmonics are relatively easier to be removed by small-size filters. Fig. 3 shows a typical power electronic converter consisting of self-commutated semiconductors such as IGBTs.

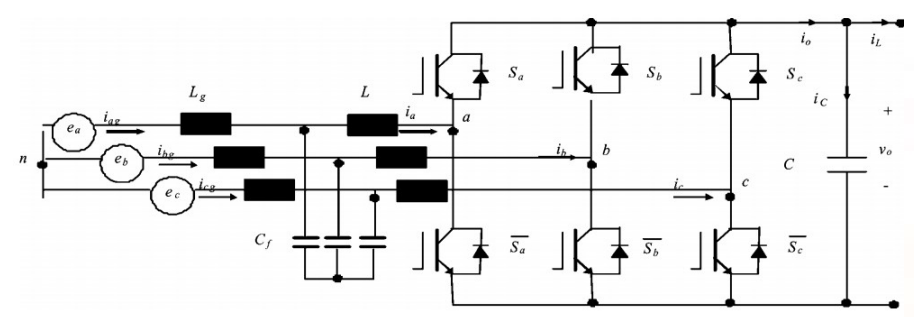

Fig. 2. Circuit diagram of a VSC with IGBTs.

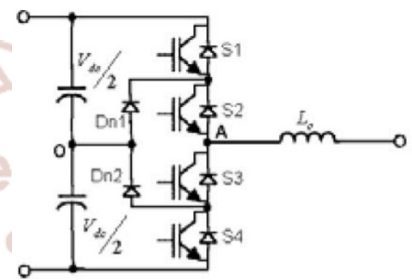

(a)

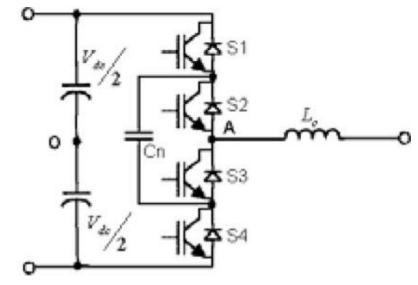

(b)
Fig. 3. Three-level VSCs. (a) Three-level neutral point clamped VSC. (b) Three-level flying capacitor VSC.

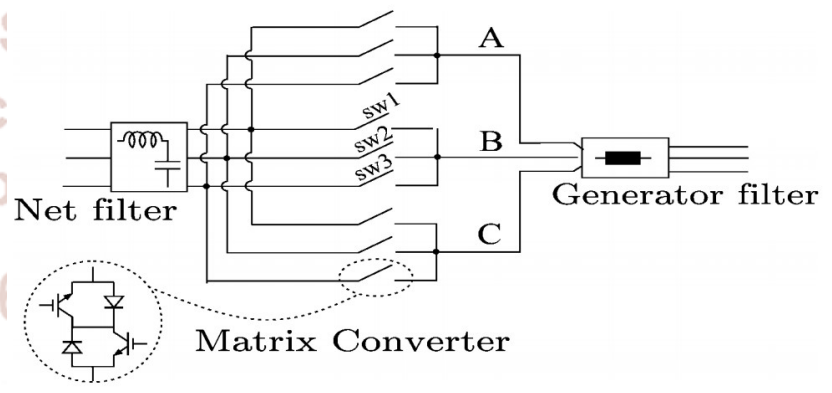

Fig. 4. Circuit configuration of a matrix converter Other types of circuit configurations also exist, including the multilevel converters, as shown in Fig. 3 , and the matrix converter, as shown in Fig. 4. Especially, the multilevel converters are very interesting in such applications due to the voltage level of the converters and the decrease of the harmonics, and consequently, the size of the output filters. The matrix converter is technically more complicated.

\section{Power Electronics for Variable-Speed Wind Turbines}

Variable-speed operation of a wind turbine system has many advantages. For instance, the wind turbine can increase or decrease its speed if the wind speed 
and torque vary. This means less wear and tear on the tower, gearbox, and other components in the drive train. Also, variable-speed systems can increase the production of the energy and reduce the fluctuation of the power injected into the grid. In variable-speed systems, the generator is normally connected to the grid through a power electronic system. For synchronous generators and induction generators without rotor windings, a full rated power electronic system is connected between the stator of the generator and the grid, where the total power production must be fed through the power electronic system [5], [6]. For induction generators with rotor windings, the stator of the generator is connected to the grid directly, and the rotor is connected to a power-electronic-controlled resistor or connected to the network through slip rings and a power electronic converter.

Fig. 5 shows four possible solutions with full-scale power converters. All four solutions have almost the same controllable characteristics since the generator is decoupled from the grid by a dc link. The grid-side converter enables the system to control active and reactive power very fast. However, the negative side is a more complex system with more sensitive electronic parts. The configurations shown in Fig. 5(a) and (b) are characterized by having a gearbox. The wind turbine system with a cage rotor induction generator and full rated power electronic converters is shown in Fig. 5(a). The synchronous generator shown in Fig. 5(b) needs a small power converter for field excitation. Multi-pole systems with the synchronous generator without a gear are shown in Fig. 5(c) and (d). The last solution uses PMs, which are becoming cheaper and thereby attractive.

\section{Power Quality Improvement With Power Electronic Devices}

Large-scale integration of wind turbines may have signifi- cant impacts on the power quality and power system operation. Traditionally, wind turbines are not required to participate in frequency and voltage control. However, in recent years, attention has been increased on wind farm performance in power systems [18]-[20]. Consequently, some grid codes have been redefined to specify the requirements that wind turbines must meet in order to be connected to the grid. Examples of such requirements include the capabilities of contributing to frequency and voltage control by continuously adjusting active power and reactive power supplied to the transmission system, the power regulation rate that a wind farm must provide, flicker, harmonics, etc. Some of the requirements may be dealt with by power electronic technology, for example, reactive power control.

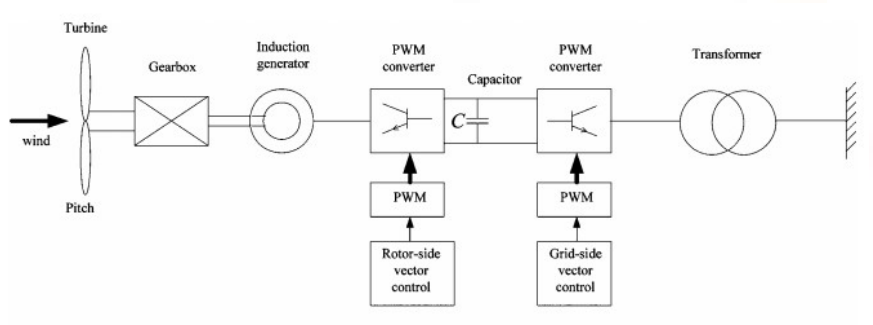

(a)

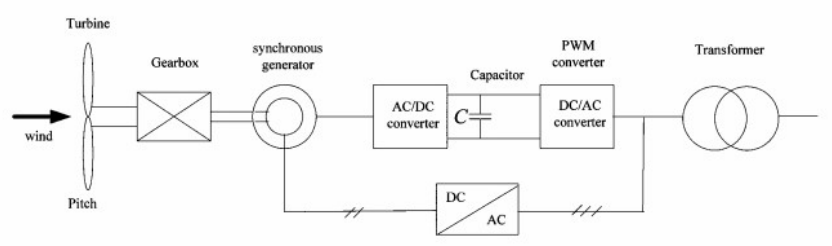

(b)

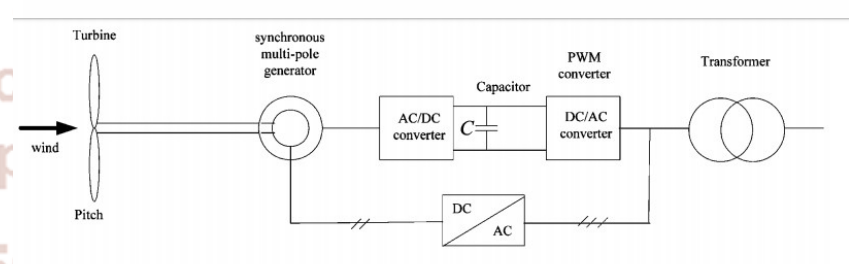

(c)

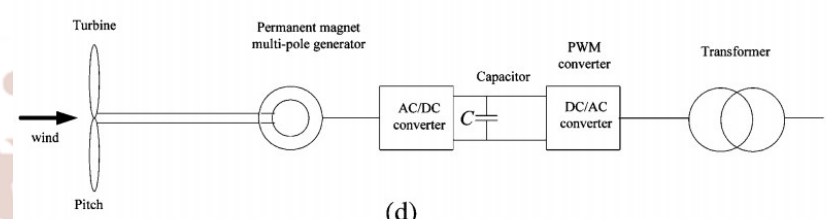

(d)

Fig. 5. Wind turbine systems with full-scale power converters. (a) Induction generator with gear. (b) Synchronous generator with gear. (c) Multi-pole synchronous generator. (d) Multi-pole PM synchronous generator.

Voltage stability problems may be derived from the need for reactive power of some wind turbines. This fact becomes more import during a voltage dip since in this case, the problem is to generate enough reactive power for the wind generators. Some existing solutions for transient and steady-state voltage control are as follows. 
1) Mechanical Switched Capacitors (MSCs): This solution, consists of a bank of shunt capacitors switched mechanically to provide reactive power compensation. The size of each capacitor may be limited in order to avoid large voltage transients. The main problems in the wind farm are that the excessive switching of the capacitor bank provokes failures, applies the inherent voltage steps stress on the wind turbines, and increases the required maintenance of the system.

2) SVCs: These systems use thyristor-controlled components, typically thyristor-controlled reactors (TCRs) and TSCs, also together with MSCs to obtain a dynamic controller of reactive power. Normally, SVCs are connected to the collector bus that connects the wind farm to the PCC to provide a desired power factor or voltage level. The SVC can adjust the reactive power, thus to basically solve the steadystate voltage problems.

TCR, which is a device consisting of three legs, each of them having an inductor and a static switch. The static switch is formed by two antiparallel connected thyristors. The power is controlled by changing the current flow through the inductor by means of the switch. The ON-state of the thyristors can be adjusted by the firing angle. However, this device generates current harmonics due to the current waveform. A TSC consists of a bank of switched capacitors. Each capacitor has an individual static switch, which is similar to a TCR device, but in this case, the switching takes place when the voltage across the thyristor is zero. Consequently, this device does not produce current harmonics. However, due to the use of switching capacitors, TSC may produce voltage transients. The combinations between these components can provide good performances of compensation. For instance, TCR can be combined with fixed capacitors or with TSC. In the first case, a TCR is used in combination with a fixed capacitor bank. This solution is often used for sub-transmission and distribution. The current harmonics may be eliminated by tuning the fixed capacitors as passive filters. The second case combines TCR and TSC in one compensator system. Hence, a continuously variable reactive power is obtained across the entire control range plus full control of both inductive and capacitive parts of the compensator.

3) STATCOM: This system, also named SVC Light by $\mathrm{ABB}$, is based on a VSC, which is used to generate reactive power. The VSC uses power electronic devices such as IGBTs, IGCTs, or gate turn-OFF thyristors (GTOs), and they can also be configured as a multilevel bidirectional converter. The VSC is connected to the grid to inject or absorb reactive power through an inductor $\mathrm{X}$. This system is suitable to mitigate both steady-state and transient events. Compared with SVCs, STATCOMs provide faster response, less disturbances, and better performance at reduced voltage levels.

\section{Conclusions}

This paper has reviewed the power electronic applications for wind energy systems. Various wind turbine systems with different generators and power electronic converters are described. Different types of wind turbine systems have quite different performances and controllability. The electrical topologies of wind farms with different wind turbines are briefed. It has been shown that the wind farms consisting of different turbines may need different configurations for the best use of the technical merits. Furthermore, the possible methods of improving wind turbine performance in power systems to meet the main grid connection requirements have been discussed. 


\section{References}

1) F. Blaabjerg, Z. Chen, and S. B. Kjaer, "Power electronics as efficient interface in dispersed power generation systems," IEEE Trans. Power Electron., vol. 19, no. 5, pp. 1184-1194, Sep. 2004.

2) Z. Chen and F. Blaabjerg, "Wind turbines - A cost effective power source," Przeglad Elektrotechniczny, no. 5, pp. 464-469, 2004.

3) M. P. Kazmierkowski, R. Krishnan, and F. Blaabjerg, Control in Power ElectronicsSelected Problems. London, U.K.: Academic, 2002.

4) Z. Chen and E. Spooner, "Voltage source inverters for high-power, variable-voltage $\mathrm{dc}$ power sources," Proc. Inst. Electr. Eng. Generation, Transmiss. Distrib., vol. 148, no. 5, pp. 439-447, Sep. 2001.

5) Z. Chen and E. Spooner, "Grid interface options for variable-speed, permanent-magnet generators," Proc. Inst. Electr. Eng. Electron. Power Appl., vol. 145, no. 4, pp. 273-283, Jul. 1998.

6) Z. Chen, S. Gomez-Arnalte, and M. McCormick, "A fuzzy logic controlled' power electronic system for variable speed wind energy conversion systems," in Proc. IEEE PEVD 2000, London, U.K., Sep., pp. 114-119.

7) T. Sun, Z. Chen, and F. Blaabjerg, "Voltage recovery of grid-connected wind turbines after a short-circuit fault," in Proc. IEEE IECON 2003, Roanoke, VA, pp. 2723-2728.

8) R. Pena, J. C. Clare, and G. M. Asher, "Doubly fed induction generator using back-to-back PWM converters and its application to variable speed wind-energy generation," Proc. Inst. Electr. Eng. Electron. Power Appl., vol. 143, no. 3, pp. 231241, May 1996.

9) Z. Chen, "Characteristics of induction generators and power system stability," in Proc. IEEE ICEMS 2005, vol. 2, pp. 919-924.

10) D. Hansen, C. Jauch, P. Soerensen, F. Iov, and F. Blaabjerg. (2003). Dynamic wind turbine models in power system simulation tool DigSilent. Report Risoe-R-1400 (EN) [Online]. pp. 1-80. Available:

11) Z. Chen and E. Spooner, "A modular, permanentmagnet generator for variable speed wind turbines," in Proc. IEE EMD 1995, pp. 453-457.
12) Z. Chen and E. Spooner, "Grid power quality with variable-speed wind turbines," IEEE Trans. Energy Convers., vol. 16, no. 2, pp. 148-154, Jun. 2001.

13) J. Twidell, "Wind turbines: Technology fundamentals," Renewable Energy World, vol. 6, no. 3, pp. 102-111, May/Jun. 2003.

14) Q. Wang and L. Chang, "An intelligent maximum power extraction algorithm for inverter-based variable speed wind turbine systems," IEEE Trans. Power Electron., vol. 19, no. 5, pp. 12421249, Sep. 2004.

15) K. Tan and S. Island, "Optimum control strategies in energy conversion of PMSG wind turbine system without mechanical sensors," IEEE Trans. Energy Convers., vol. 19, no. 2, pp. 392-399, Jun. 2004.

16) S. Bhowmik, R. Spee, and J. H. R. Enslin, "Performance optimization ' for doubly-fed wind power generation systems," IEEE Trans. Ind. Appl., vol. 53, no. 4, pp.949-958, Jul./Aug. 1999.

17) A. B. Raju, K. Chatterje, and B. G. Fernandes, "A simple maximum point tracker for grid connected variable speed wind energy conversion system with reduced switch count power converters," in Proc. IEEE PESC 2003, vol. 2, pp. 748-753.

18) Power Quality Requirements for Wind Whines, IEC Standard 61400-21, 2001.

19) DEFU, Connection of Wind Turbines to Low and Medium Voltage Networks, the Committee Report KR-111-E, 2nd ed. Copenhagen, Denmark: DEFU, Oct. 1998.

20) Wind Turbine Generator Systems. Power Performance Measurement Techniques, IEC Standard 61400-12, 1998. 